\title{
FUNDAMENTOS DE UN MODELO DE FORMACIÓN PERMANENTE DEL PROFESORADO DE CIENCIAS CENTRADO EN LA REFLEXIÓN DIALÓGICA SOBRE LAS CONCEPCIONES Y LAS PRÁCTICAS
}

\author{
COPELLO LEVY, MARIA INÉS ${ }^{1}$ y SANMARTÍ PUIG, NEUS ${ }^{2}$ \\ ${ }^{1}$ Universidade Federal do Rio Grande. (FURG). Brasil \\ ${ }^{2}$ Universitat Autònoma de Barcelona (UAB)
}

\begin{abstract}
SUMMARY
In this article, principles of one model for male and female Science teacher formation are discussed, considering as its basis the dialogical and critical reflection on concepts and practices, between the teacher and his/her tutor. The dialogical reflection takes place due to problems located in a concrete environment, which are scrutinized in the light of modern theoretical references regarding to the learning-teaching process of Sciences. The model is based on socioconstructivist currents and, very specially, on studies about the role of self-regulation and learning metacognition. The principles discussed are illustrated with transcription fragments of dialogues obtained through model experiencing in a progressive formation project for Biology secondary teachers in Rio Grande (RS), Brazil.
\end{abstract}

\section{LA FORMACIÓN DEL PROFESORADO DE CIENCIAS: UNA DE LAS PRIORIDADES PA- RA MEJORAR LA EDUCACIÓN CIENTÍFICA}

El análisis de cómo se enseñan las ciencias en Brasil y en España nos lleva a afirmar que existe una profunda distancia entre las propuestas curriculares, que acostumbran a ser consecuencia de teorías didácticas surgidas de la investigación educativa y de planteamientos socioeconómicos, y las acciones que realmente se llevan a cabo en las escuelas.

Generalmente todo cambio curricular va acompañado de una considerable inversión en formación del profesorado, pero su efectividad en cuanto al cambio de la práctica es mínima. Pueden cambiar la estructura de un centro, la de una etapa educativa o el currículo y, en el caso de la enseñanza de las ciencias, pueden cambiar algo (muy poco) los contenidos que se enseñan, pero no varían las concepciones sobre qué es importante enseñar, sobre cómo hacerlo, sobre las causas del fracaso de unos estudiantes al aprender ciencias...

A través de numerosos estudios (Guess-Newsome, 1993; Gustafson y Rowel, 1995; Cobern, 1996; Hasweh, 1996; Mellado, 1996; Porlán y Rivero, 1998) se ha puesto de manifiesto el «pensamiento» del profesorado: sus ideas acerca de la ciencia, de la enseñanza y del aprendizaje. Estos trabajos muestran que, igual que cuando se estudiaron las concepciones alternativas del alumnado sobre las explicaciones de los fenómenos de la naturaleza, los enseñantes tenemos nuestra mente «lle- 
na» de ideas, acompañadas de rutinas muy bien establecidas, que son extraordinariamente estables y difíciles de cambiar.

Paralelamente se sabe (Gil y Pessoa, 1994; Pérez Gómez, 1992) que se tiende a enseñar más como se aprendió en la escuela y en la universidad que aplicando las ideas «aprendidas» sobre cómo se debería enseñar. También está demostrada la importancia del primer año de ejercicio de la profesión en la definición de las concepciones y prácticas sobre la enseñanza: éstas dependen mucho del tipo de escuela en la que se empieza a ejercer, de las prácticas observadas en los compañeros más expertos, de sus ideas expresadas en las discusiones de los claustros y en las horas de la comida o asueto...

Después de la Segunda Guerra Mundial, paralelamente a la democratización del sistema educativo, la enseñanza de las ciencias ha pasado, de ser algo dirigido sólo a unas minorías, a generalizarse para toda la sociedad. Ello ha promovido la necesidad de investigar cómo dar respuesta a los problemas que surgen al enseñarla, desde qué se entiende por ciencia, o qué ciencia es importante enseñar desde el punto de vista social y humano, hasta cómo conseguir que todos se apropien de este tipo de conocimiento construido a lo largo de siglos de historia de la humanidad. Los conocimientos actuales en el campo de la didáctica de las ciencias son mucho mayores que hace cincuenta años; sin embargo, las prácticas han cambiado muy poco.

Este desfase plantea problemas no resueltos. La investigación avanza mucho más rápidamente que la práctica (Gimeno Sacristán, 1991). Mientras que un descubrimiento en el campo de la ciencia tarda muy poco en ser aplicado, un nuevo conocimiento en el campo educativo tarda generaciones en generalizarse (Sanmartí y Izquierdo, 1997).

En países como Brasil o España, la inmensa mayoría de los enseñantes se mantienen en la profesión durante toda su vida laboral. Un profesor puede haber vivido como estudiante y como enseñante un mínimo de cuatro cambios curriculares importantes y, sin embargo, sus concepciones y sus prácticas educativas pueden haber cambiado muy poco e, incluso, haber retrocedido hacia puntos de vista más tradicionales. Ello muestra que el problema es importante y que requiere diseñar e implementar acciones innovadoras en la formación inicial y permanente del profesorado. Estas acciones deberían tener como objetivo hacer viables cambios en los procesos de enseñanza que repercutan en mejoras en el aprendizaje del alumnado y que, a la vez, incidan en la autovalorización y autoestima profesional.

La formación de profesores de ciencias, tanto inicial como permanente, es uno de los campos de la investigación educativa en evidente expansión. Existe consenso de muchos autores en la opinión de que ésta es una de las formas eficientes de alcanzar mejoras en el proceso de enseñanza-aprendizaje (Baird et al., 1991; Escudero, 1991; Clarke, 1994; Gunstone y Northfield, 1994; Mitchell, 1994; Porlán, 1994; Briscoe y Peters, 1997;
Porlan y Rivero, 1998). Porlán y Rivero (1998) afirman que para desencadenar procesos de suficiente extensión y profundidad, que dejen huellas en el conjunto del sistema, es necesario trabajar con estrategias complejas de cambio, que traten de incidir en las diferentes variables de lo que ellos denominan «contexto». Dentro de este contexto, la implicación activa, consciente e interesada de los profesores/as es imprescindible; sin ella ningún tipo de cambio es posible.

Desde nuestro punto de vista, las acciones formadoras deben llevar a que el profesorado alcance una fundamentación teórica de su actuación, congruente con los nuevos conocimientos que sobre el proceso de enseñanzaaprendizaje de las ciencias se van elaborando, y a que, conjuntamente, sepa vincular estos conocimientos a su práctica. Como también es necesario que se den cambios en el sistema de valores y actitudes, a nuestro entender es imprescindible que todo el proceso de formación se vincule a una reflexión crítica tanto en relación con la forma actual de enseñar ciencias como a las posibles innovaciones planteadas. Y todo ello teniendo muy en cuenta la consideración del contexto sociocultural de actuación y el mundo emocional del que enseña. Dicho proceso debe favorecer tanto la capacidad de actuación en las condiciones del espacio concreto de trabajo (Domingos, 1989) como potenciar la autoestima y la obtención de placer en el ejercicio de la profesión.

Por todo eso, el objetivo de nuestro trabajo, lo centramos en el desarrollo de un modelo de formación didáctica del profesorado de ciencias que, partiendo de sus concepciones y de sus prácticas, favorezca una toma de conciencia y de decisiones que, a su vez, genere mejoras en el proceso de enseñanza-aprendizaje en el aula. Ello implica que las variables «contexto de aplicación»y «contexto de cada enseñante» sean puntos de partida importantes.

\section{LA FORMACIÓN DEL PROFESORADO DE CIENCIAS: UN PROBLEMA NO RESUELTO}

La formación permanente del profesorado de ciencias no es un problema fácil. Está comprobado que una inversión significativa en formación, tal como se ha hecho en algunos momentos en Brasil, España u otros países, no se traduce en mejoras significativas en la calidad de la enseñanza.

Astolfi (1998) señala que, en general, al proponerse experiencias innovadoras, después de un inicio entusiasta, se oscila frecuentemente entre resultados positivos que nos llevan a afirmar que estamos en el camino cierto y una cierta decepción en relación con las fuertes expectativas iniciales. «Desearía desarrollar la idea de que esta situación no es desesperante y no debe llevar a la desmovilización sino que, al contrario, corresponde a una realidad que se debe afrontar con el máximo de claridad y lucidez posibles» (Astolfi, 1998, p. 376). 
Todo aprendizaje, y en especial el aprendizaje científico, es complejo y resulta de una multiplicidad de factores. Habitualmente, en un curso o actividad de formación, se incide en alguna de las variables, y el profesorado tiende a aplicar alguna de las ideas, estrategias, recursos o técnicas desarrolladas, sin que ello implique un cambio en otras variables. Como habitualmente los resultados no son los esperados -los cambios en educación acostumbran a ser muy pequeños y observables sólo a largo plazo-, rápidamente se vuelve a las rutinas anteriores. También puede ocurrir que las nuevas prácticas, especialmente cuando se trata de la aplicación de recursos o herramientas puntuales, se incorporen a los modelos de enseñanza antiguos y se apliquen desde planteamientos que no concuerdan con la nueva propuesta, con lo cual ésta se desvirtualiza totalmente. Pensemos, por ejemplo, en cómo a veces se aplican nuevos trabajos prácticos o en cómo se utilizan instrumentos del tipo mapas conceptuales, bases de orientación, técnicas de lectura o de estudio...

En general, los modelos de formación permanente del profesorado se desarrollan alrededor de dos grandes tipologías:

- La más extendida consiste en la realización de cursos sobre temas muy específicos o sobre nuevas orientaciones. Creemos que, aunque los temas tratados en ellos sean importantes y relevantes para el profesorado, al estar esta modalidad habitualmente alejada de su campo de actuación, la formación corre el riesgo de ser algo externo, algo que el profesorado tendrá que integrar luego, por su cuenta, a su espacio de actuación. De este modo, aunque en los cursos se fundamenten teóricamente las nuevas propuestas, éstas quedan reducidas al plano del discurso y no acostumbran a incorporarse a la práctica cotidiana de las clases (o sólo se integran las técnicas o recursos concretos, sin cambiar las concepciones). Únicamente en el caso de que dicho discurso coincida con el de los asistentes al curso, éstos podrán transformar su teoría y su práctica. Por eso los cursos sólo son útiles para una minoría reducida del profesorado, es decir, para aquéllos que ya comparten el marco teórico de referencia.

- En los últimos años también se ha extendido en muchos países, entre ellos España, pero menos en Brasil, la modalidad de formación en el propio centro de trabajo, a partir del planteamiento de temáticas susceptibles de interesar a todo el profesorado. No hay duda de que esta modalidad tiene muchas ventajas, ya que se desarrolla en el propio contexto y tiene como finalidad transformar la práctica. Sin embargo, se supone que el profesorado transferirá fácilmente los aspectos psicopedagógicos generales tratados en su práctica de enseñar ciencias (u otra disciplina). Desde nuestro punto de vista, si no se promueve al mismo tiempo la reflexión epistemológica y la psicopedagógica en relación con el área del saber, es difícil que llegue a cambiarse la práctica de enseñar ciencias, por lo que no es de extrañar que también, en esta modalidad de formación, las concepciones y las prácticas de enseñanza cambien muy poco.
No hay duda, pues, de que, del problema de la formación permanente del profesorado, se sabe muy poco. Seguramente los modelos más válidos serían los que posibilitasen la formación simultánea desde la doble perspectiva institucional y específica en el área de enseñanza (ver, por ejemplo, las experiencias del FOPI (Departament d'Ensenyament [1987] o el Plan de Formación diseñado por el Instituto Municipal de Educación del Ayuntamiento de Barcelona [1990]). Aun así falta mucho para poder disponer de un modelo o diversos modelos de formación permanente válidos para responder a las necesidades diversas de la mayoría del profesorado (y no sólo a las de los más predispuestos al cambio).

Paralelamente, otra de las variables a estudiar en la formación del profesorado se refiere al tiempo necesario para que se transformen las concepciones y las prácticas. Parece alejado de toda duda que la formación permanente debería ser planificada siempre a largo plazo. Esta necesidad armoniza mal con el interés de las administraciones públicas en mostrar resultados inmediatos, por lo que en la mayoría de las actividades de formación promovidas por aquéllas se prima la cantidad por encima de la calidad.

\section{CARACTERÍSTICAS ESTRUCTURANTES DE LA PROPUESTA DE FORMACION PLANTEADA}

Para dar respuesta a los problemas señalados anteriormente, abogamos por profundizar en las líneas de actuación que proponen revisar la práctica sobre la base de un posicionamiento teórico: «saber hacer fundamentado» (Porlán y Rivero, 1998) o «praxis educativa» (Grundy, 1991). Esta revisión creemos que debe ser de naturaleza metacognitiva (Gunstone y Northfield, 1994), es decir, debe desarrollar habilidades metacognitivas que favorezcan el reconocimiento de posibles causas de los problemas o dificultades detectados en la práctica y, a su vez, que posibiliten la autorregulación de los cambios conceptuales, procedimentales y actitudinales a introducir en el proceso de enseñar ciencias.

Como ya se ha indicado, se ha pretendido estructurar la formación del profesorado de ciencias de tal forma que posibilite que cada profesor o profesora, trabajando en el espacio de sus concepciones y de sus prácticas, tome conciencia de ellas y adopte decisiones que, a su vez, generen mejoras en el aprendizaje de sus alumnos.

La formación permanente que proponemos se caracteriza por reunir al profesorado del área en una acción intercentros. La realidad concreta para la cual se delineó esta metodología fue el profesorado de biología de secundaria de la ciudad de Rio Grande, Brasil. Para una población de unos 200.000 habitantes, el total de profesores y profesoras de dicha especialidad es de 26 , que trabajan individualmente, la mayoría, o bien sólo dos por institución. 
La experiencia de la que se han extraído los datos aquí transcritos se llevó a cabo con cuatro profesores $(\mathrm{P})$ y una orientadora (O), durante un curso escolar (1996-97). Para ello, se planteó el esquema de actuación desarrollado en la figura 1, en el que destacaríamos los siguientes pasos:

a) Propuesta a profesoras de biología para participar en un proceso de formación con la finalidad de mejorar su práctica de enseñanza de dicha disciplina y conseguir que sus estudiantes la aprendan más significativamente. Inicio de planteamiento de problemas, dudas, necesidades.

b) Observación de la actuación de cada profesora (grabación en vídeo) seguido de «encuentro inicial» (entrevista) entre cada profesora y la orientadora, en la que ambas manifiestan sus concepciones sobre el proceso de enseñanza-aprendizaje de las ciencias. Su finalidad: iniciar la reflexión dialógica para promover la explicitación de las dificultades, de las «cosas que funcionan», de las incoherencias, de las explicaciones de todo ello... y de las posibles necesidades de cambio (o de continuidad). La orientadora aporta fundamentalmente referentes teórico-prácticos actualizados del campo de la didáctica de las ciencias -lecturas, investigaciones, experiencias distintas...-, y la profesora, su realidad, el contexto de su práctica y sus ideas implícitas. Ambas aprenden conjuntamente, ya que no hay recetas preelaboradas que permitan predecir cuál sería una «buena» actuación.

c) Autorreflexión individual, tanto por parte de cada profesora como de la orientadora, realizada a partir de la observación del vídeo, de leer la transcripción del encuentro inicial y de profundizar en algún aspecto teórico.

d)Primera reflexión dialógica coevaluativa y autoevaluativa, en la que cada profesora y la orientadora ponen en común y comentan las reflexiones anteriores. $\mathrm{Su}$ finalidad es plantear posibles hipótesis de cambio y argumentarlas.

e) Encuentro de todo el grupo, en el que se contrastan las distintas hipótesis y se intercambian puntos de vista para llegar a decidir posibles cambios a introducir.

f) Preparación de una unidad didáctica innovadora, de forma cooperativa entre cada profesora y la orientadora.

g) Observación de la aplicación de dicha unidad didáctica (nueva grabación en vídeo) que es acompañada, concomitantemente y al final, de la segunda reflexión dialógica de análisis de dicha práctica. Planteamiento de nuevas posibles hipótesis de cambio (y de continuidad).

La experiencia analizada en este escrito terminó en este punto, aunque posteriormente continuó con un menor grado de intervención por parte de la orientadora. De la misma forma podrían surgir entrevistas dialógicas entre las propias profesoras o que alguna de ellas se transformara en orientadora de otros enseñantes adheridos al proyecto.
Una de las críticas que seguramente podría hacerse a este proceso de formación es su alto costo, sobre todo en tiempo y en la necesidad de la dedicación personalizada de la orientadora. Aun siendo cierto, los resultados nos llevan a afirmar que la estrategia resulta eficaz y rentable a largo plazo. Es una estrategia que permite adecuarse a la individualidad de cada profesor/a, y llevarlo o llevarla a un proceso crítico de toma de conciencia y a participar en la elaboración de la toma de decisiones. Como resultado se van produciendo cambios lentos, pero significativos y, pensamos, persistentes en su mayoría, tal como se confirma en la experiencia realizada. Frente a grandes inversiones económicas asociadas a otros modelos de formación pemanente que a la larga resultan poco eficaces, creemos que esta propuesta es una alternativa válida y que no puede dejar de ser considerada, sobre todo para comunidades no muy grandes.

Otras de las críticas podrían referirse a que el proceso en buena parte es individualizado. Tal como argumentaremos, ello no se opone a actividades de reflexión de todo el grupo que participa del proceso; por el contrario, las incluye y, sobre todo, es importante que los participantes se sientan pertenecientes a dicho colectivo, con un objetivo común a todos sus miembros.

\section{FUNDAMENTOS TEÓRICOS DEL MODELO DE FORMACIÓN APLICADO}

Aunque, tal como veremos, la línea de trabajo desarrollada se fundamenta en corrientes socioconstructivistas $\mathrm{y}$, muy especialmente, en los estudios acerca de la función de la autorregulación y de la metacognición en el aprendizaje, también se han tenido en cuenta otras líneas. Como dice Shulman (1989), la existencia en el área educativa de diferentes modelos y programas de investigación que se suceden o coexisten no es una debilidad del área sino una tendencia saludable que permite tener en cuenta una amplia gama de determinantes que influyen en la práctica de la enseñanza y sus consecuencias.

Detrás de cada práctica de enseñanza hay diferentes concepciones que constituyen el punto de partida de todo proceso de formación permanente. Subyacen diferentes formas de entender qué es la ciencia, qué es aprender, qué es un buen trabajo práctico o un problema, qué es la evaluación, cuáles son las causas del fracaso escolar, etc. Pero también hay muchas rutinas aprendidas al inicio de la profesión, bien vividas anteriormente como alumnos, bien imitadas de compañeros más expertos, que aplicamos constantemente en el momento de tomar decisiones.

Sólo en ciertas ocasiones, por ejemplo, al asistir a un curso de formación o en un conflicto, utilizamos el consciente. Pero hacerlo es siempre más costoso y, como difícilmente se pueden observar resultados rápidos, volvemos a las prácticas anteriores. Cuando aprendemos a conducir, vemos rápidamente la utilidad de corregir un 
Figura 1

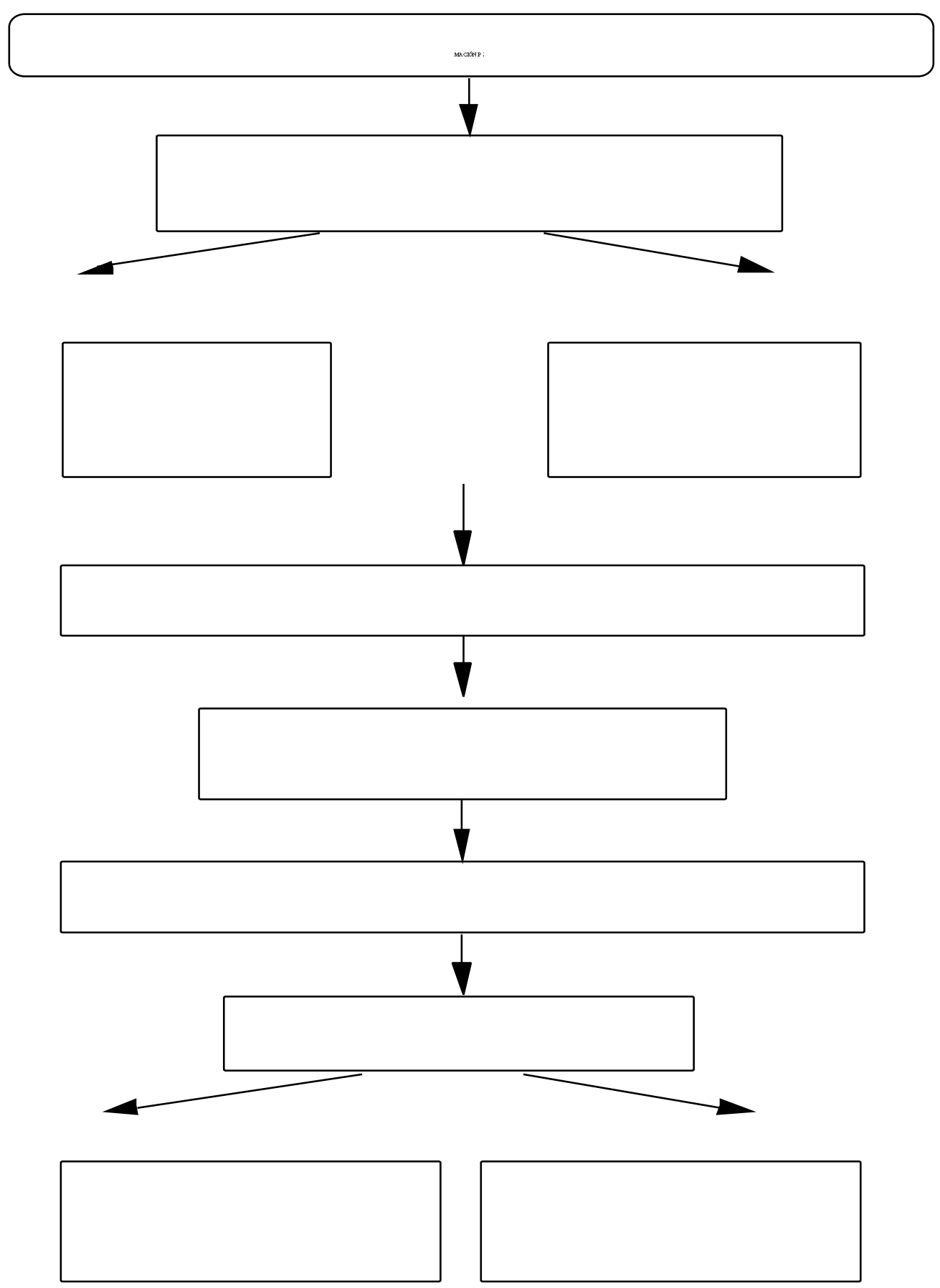




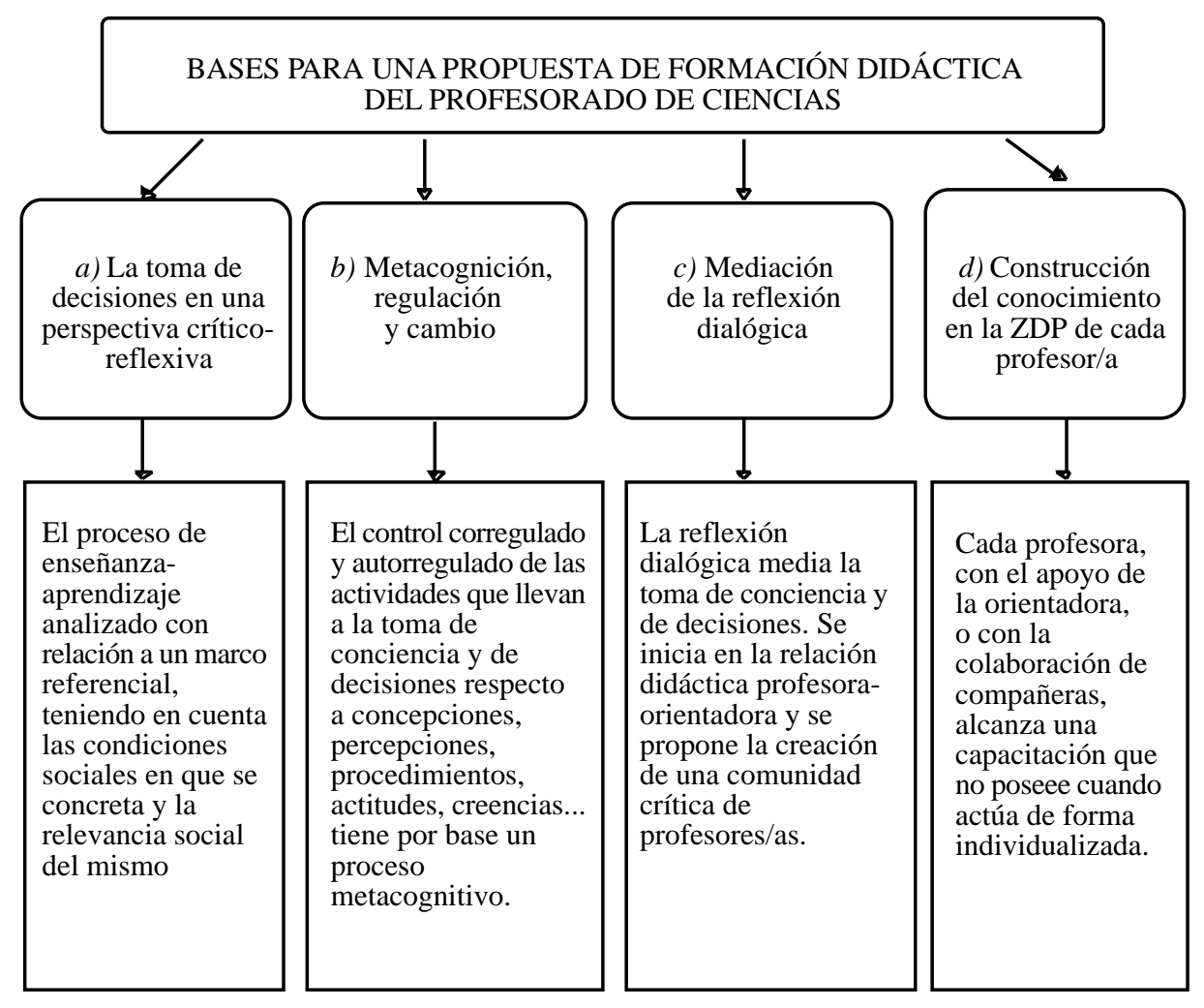

error, pero los resultados de un proceso de enseñanza aplicado en el aula sólo se reconocen al cabo de mucho tiempo. Además, se tiende a pensar que las causas no se encuentran en el sistema didáctico aplicado, sino en factores externos: el «sistema», los alumnos, sus familias, los compañeros, el tiempo, los medios de que disponemos...

Por ello, en la formación para la profesión de enseñar influyen de forma importante otros factores como: el grupo del que se forma parte, si se comparten o no retos, ilusiones, intereses, etc. La evaluación y regulación del proceso de formación no sólo está condicionada por los resultados inmediatos, también influye de forma decisiva cómo el grupo de que forma parte el profesor/a valora el mismo

Desde todos estos referentes iniciales se diseñó un modelo de formación basado fundamentalmente en cuatro aspectos (Fig. 2).

\section{El profesor/a toma decisiones como sujeto reflexi- vo-crítico}

Un primer componente que da base al modelo de formación diseñado consiste en que el profesor/a sea orientado a realizar un proceso reflexivo y de carácter crítico. Vamos, pues, a argumentar sobre las connotaciones con que se entiende ese proceso de reflexión y las características que le confieren el carácter de crítico.

El modelo de formación del profesor/a como sujeto reflexivo crítico (Grundy, 1991; Kemmis 1993; Perrenoud, 1993; Zeichner 1995; Carr, 1996; Porlán y Rivero, 1998) aboga por una reflexión deliberadora sobre las concepciones y prácticas del profesor/a que tenga por base:

1) Un marco teórico referencial del proceso de enseñanza-aprendizaje de las ciencias. La formación didáctica del profesorado tiene como objetivo generar mejoras en dicho proceso, tal como es aplicado en el aula. Sin embargo, hay distintos referentes teóricos en función de los cuales se pueden defender diferentes concepciones: algunas son complementarias y otras netamente contradictorias. Por ello es importante reconocer la posible coherencia de nuestra actuación en función del marco teórico de referencia explicitado constantemente por la orientadora. Veamos ejemplos sobre cómo se concreta esta idea en los siguientes fragmentos de los «Encuentros de reflexión» que formaron parte de la experimentación: 
Orientadora: -Observa ahora qué [tipo de actividades] aparece menos en tus clases. [La profesora analiza la gráfica elaborada por la orientadora que muestra la distribución del contenido de las interacciones profesora-alumnado en su clase.]

Profesora: -Una conversación «extra-clase» dentro del horario de clase. ¿Qué es eso? Eso no lo entendí. ¿Conversación informal con los alumnos y alumnas sin ser del contenido de la clase?

o: -Sí, eso. Una conversación en el transcurso de la clase que nada tiene a ver con el tema de clase. Significa que no tiene ninguna relación con la unidad. Es una «charla» amistosa entre profesora y alumnos/as.

P: -¿Es una «charla» con los estudiantes en la hora que está dedicada a la clase, no en el patio?

O: -Sí. ¿Qué opinas de que eso en tus clases sea tan poco significativo?

P:-Bueno, en mi propuesta, por lo que yo pienso, por las cosas en que acredito, opino que está bien. Pienso que no me gustaría haber ocupado más tiempo con "conversación nada a ver». Mismo que creyese que es importante dejaría para otra hora, no sé... Depende del asunto también... Pero no, si es asunto "extraclase», no tiene nada a ver, realmente no hablaría... dejaría para otra hora. Con las rutinas de aula, hasta que ocupo un poquito, pero no gustaría de que ocupase más que eso. Quedo satisfecha con esto. ¡Concuerda con lo que yo pienso!

O:-Yo también estoy de acuerdo. A partir del marco teórico en el que nos situamos, la relación en clase es una relación entre tres elementos: saber-estudiantes-profesor/a. Entonces, yo pienso que allí el estudiante es estudiante. No quiere decir que fuera del horario de clase no estimulemos esas conversaciones puramente de amigos. Tampoco de que si, en determinado momento, surge una situación a la que es importante prestarle atención inmediata, ahí no tengas que realmente hacerlo. Pero, como cosa general, realmente estoy de acuerdo en que alumnos/as y profesor/a están interactuando con relación a un saber que están trabajando. Vuelvo a decir, dentro del marco teórico adoptado. Tal vez alguien orientado por una línea «rogeriana», humanista, confiriese un valor diferente a nosotros a esas "charlas de amigos» durante la clase... O sea, eso lo defendemos dentro de nuestro marco teórico que podemos llamar de «constructivismo cognitivo-social». Valoramos la interacción social, sin embargo, relacionada con una construcción cognitiva, con el saber de la disciplina que estamos trabajando. Entonces, no diría que es correcto o equivocado, pero sí, que es coherente con una postura dentro de la cual nos proponemos trabajar. [La reflexión dialógica PA]

O: -...Y en tus clases, vuelvo a decirte, un aspecto para tal vez tomar muy en cuenta es la motivación totalmente diferente que se aprecia de un momento para otro.

P: - Nosotras hablamos sobre eso en la otra reunión: el momento de los ejercicios... Yo tengo pensado bastante sobre esto. iRealmente yo tengo que modificar eso ahí! Porque me causa angustia, y yo ya había notado también eso, cuando tu hablaste yo ya había notado, la clase parece que para, la motivación va para bien abajo. [La reflexión dialógica $\mathrm{PB}]$

O: -El aspecto de la relación profesora-alumnos/as ya es una conquista totalmente lograda, pero desde un punto de vista de relación interpersonal entre vosotros. Tú podrías dar unas clases más desmotivantes, que ellos pondrían buena voluntad, no por el tema o el método sino por tí, como consecuencia de la interacción social, interacción afectiva que existe entre tú y el grupo, el grupo y tú.

P: -Con todas los grupos, normalmente es así.

O:-Se percibe: tú vas llegando y haces una broma, otra, y todo dentro de una situación de amistad respetuosa... entonces eso es una cosa que tú ya has construido. Lo que yo creo que quedó introducido como nuevo fue el placer en el trabajo conjunto... lo que cambió fue el tipo de saber que trabajaron. No sucedió como decíamos antes.

P: -El momento de los ejercicios.

O: -Eso. «Tomar la medicina» juntos. Entonces ellos lo soportaban porque te apreciaban... En cambio yo diría que conseguisteis, como diría... introducir harmonía en todo el triángulo: vosotros y a teníais establecida una interacción muy positiva entre profesora-alumnos/as, pero faltaba la interacción afectiva con el saber. Entonces esa interacción afectiva con el saber pasó a existir y, al mismo tiempo, pasó a existir otro tipo de contrato didáctico en el aula.

$P:-E s o$ es una cosa que encontré muy importante. Ése fue uno de los aspectos en que nuestro trabajo sirvió para darme una claridad que yo no tenía. Lo encontré muy interesante y tengo el mayor interés en continuar con este tipo de trabajo; creo que realmente vale la pena. Creo que la experiencia dio para percibir que el camino va por ahí. [2a reflexión dialógica PB]

2) Que la atención se centre tanto en la propia práctica como en las condiciones sociales en que esa práctica se lleva a cabo y en la relevancia social de la misma. La práctica reflexiva tiene en cuenta cuestiones relativas a las dimensiones sociales y políticas del ejercicio docente; por ejemplo, los asuntos de género, raza, clase social, dimensión ética de la ciencia y la tecnología están presentes en la cotidianidad de las clases de ciencias. Kemmis (1993) dice que, para que un grupo de personas llegue a ser una comunidad «crítica», debe, en primer lugar, cumplir el prerrequisito de ser una comunidad. Pero, además, debe producirse un reflexión deliberadora que problematice poniendo en cuestionamiento el contexto. Veamos cómo se concreta esta otra idea en los siguientes fragmentos extraídos de los «Encuentros de Reflexión»:

P: -Y algunas veces, es lo que ya te hablé: era eso que me angustiaba, que me dejaba cada vez más... algunas veces hasta depresiva. Yo digo así: ‘Caramba! iParece broma! Tenemos alumnos que quieren crecer, ellos ni saben que quieren crecer pues y a se acostumbraron a esa situación, con ese cotidiano. Y allí ni saben que quieren crecer, pero inconscientemente lo quieren, quieren ser alguien en la vida. En contrapartida, tenemos una escuela en estas condiciones de realidad que ella presenta.

O: -Yo coincido totalmente contigo. Es importante...

P: $-Y$ ahí acaban desinteresándose, yendo para otro camino y separándose cada vez más de la escuela.

O:-Tenemos que construir una escuela diferente. Te voy leer una cita de un libro que leí estos días [La orientadora recoge un libro de la biblioteca que está en la sala.] «Enguita ejemplifica la alienación de los alumnos en relación con sus medios de producción del conocimiento: espacios transparentes, patios de recreo vigilados, entradas controladas, dependencias sin cerradura en los baños, sumados a la falta de un espacio propio que no sea la clase, además de posibilitar la vigilancia constante, recuerdan a los niños y jóvenes que el territorio de la escuela no es, de ninguna forma, su territorio». [Enguita, 1989, p. 185]

P: -Exactamente.

P: -También ellos [los estudiantes] están muy reprimidos ahí afuera

O: -¿Reprimidos por quién?

P:-Por el padre, por la madre, sufren una cierta represión por la propia sociedad. Y entonces en el momento en que los profesores/as también reprimen, los estudiantes se rebelan contra ellos. 
Entonces, no [debemos reprimir], debemos trabajar en base al diálogo, a la conversación.

P:-En total trabajo con 7 grupos con una media de 35-40 alumnos en cada uno.

O: -Entonces son más de 200 alumnos/as.

P: -Sí, es muy difícil, es muy difícil recordar los nombres. Algunas veces en los consejos de clase hablamos de alumnos/as que yo no sé quienes son. Me dan sus características, pero no consigo realmente ponerles cara. Sólo consigo conocer los alumnos/as, saber quién es cada uno, a fin del año.

3) Que la práctica reflexiva esté comprometida con el grupo en la que se produzca. Se trata de crear comunidades de aprendizaje en las que los profesores apoyen y sostengan el progreso de cada uno. En nuestra propuesta se parte, al inicio del proceso, de una reflexión dialógica corregulada entre cada profesora y la orientadora. Sin embargo, también desde el principio se llevan a cabo acciones orientadas a promover que el conjunto de profesoras participantes reconozcan que forman parte de una comunidad. En su marco, se evidencian los diferentes puntos de vista y prácticas, y se favorecen procesos de corregulación y autorregulación. Los siguientes fragmentos de los «Encuentros de Reflexión» ilustran ese aspecto:

P: -Yo creo que lo más importante de todo esto fue que, tú [la orientadora] surgiste en una hora, así, iluminada. Yo estaba sintiéndome angustiada, por el hecho de ver que había caído en la rutina. La manera cómo estaba trabajando no me gustaba. Entonces, esta formación fue romper la rutina... Yo creo que ese hecho fue muy importante. Después, ese intercambio de experiencias que tuvimos... [Se refiere a una reunión colectiva de todas las profesoras y la orientadora y a la lectura que hizo de fragmentos de las entrevistas de las compañeras y la orientadora.] Que yo quedé sabiendo que la angustia no era solo mía, era también de otras personas. Y el hecho de que hayamos conseguido hacer este trabajo! [Se refiere a la última unidad preparada en forma colaborativa.] iY todavía voy a quedar más satisfecha si conseguimos llevar esto adelante. Porque hoy es una cosa pequeñita, es una cosa que prácticamente quedó entre nosotras, pero en el futuro tengo la seguridad de que esto se va a transformar en una onda y va a acabar modificando [la enseñanza de la biología en la comunidad], va a surtir efectos. Entonces, creo que el hecho más importante para mi fue ese salir de la rutina, el trabajar con compañera. Estaba necesitándolo. Creo que tuvo un efecto positivo. Lo vas a ver cuando mires los trabajos de los estudiantes. Y también en la relación con ellos, incluso en la relación con los alumnos, ellos mostraron que aquello que estaban haciendo les gustaba.

O:-Ahora nosotros dos acabamos de pensar un trabajo diferente, en base a una dramatización. Si nos juntamos para pensar, se nos van a ocurrir mil ideas. $Y$ lo hacemos compartiendo en un grupo donde una piensa una cosa, otra piensa otra.

P: -iPodemos hacer maravillas!

O:-Continuaremos con el sueldo indecente. Cambiar eso es otra lucha que está fuera de los límites de nuestro proyecto. Sin embargo, por lo menos va ser mucho más bonito y divertido y nos vamos a sentir mucho más útiles.
O:-Pienso [...], es que en este momento hemos hecho un proceso de concientización y hemos pensado en decisiones de cambio o continuidad a partir de esta reflexión conjunta. En ese sentido creo que ya conseguimos bastantes cosas. Si colaboramos, podemos introducir algunas innovaciones y, si luego compartimos esto con las compañeras, podemos mejorar bastante.

P: -Pues, mira, como yo te hablé al inicio, ya me gusta trabajar sola y creo que no estoy rutinizada, procuro siempre estar inventando cosas. Ahora bien, adoro trabajar en grupo, comunicarme. Entonces, no sé cuánto voy a poder hacer de nuevo, pero que voy a intentarlo y que voy a divertirme, que voy adorar este trabajo, de eso sí que puedes tener seguridad.

Para Schön (1983), tres conceptos diferentes se incluyen bajo la idea de pensamiento práctico: a) conocimiento en la acción; $b$ ) reflexión en la acción; y c) reflexión sobre la acción y sobre la reflexión en la acción según que el proceso de reflexión sea previo, simultáneo o posterior a la acción. Zeichner (1987), refiriéndose a las situaciones de aula, dice que la «reflexión en la acción» es difícil, pues el propio ritmo de la clase no es siempre compatible con actitudes reflexivas y generalmente actuamos sobre todo intuitivamente. Sin embargo, no deja de reconocer su valor, siempre que sea posible, como apoyo a los otros momentos reflexivos.

La reflexión sobre la acción y sobre la reflexión en la acción puede considerarse como el análisis realizado con posterioridad a la acción. Astolfi y otros (1991, p. 175) usa la expresión reflexión distanciada y dice que es «toda situación en que el sujeto es llevado a lanzar una mirada de otra naturaleza sobre lo que hizo o aprendió. Este tipo de mirar induce a un distanciamiento que autoriza críticas y permite la descentralización, siendo de esta manera un facilitador para que ocurran reelaboraciones».

El modelo diseñado se centra en esta reflexión distanciada y parte de la hipótesis de que el ejercicio de la misma llevará, gradualmente, tanto a la estructuración de nuevas rutinas fundamentadas como a una actitud reflexiva en determinados momentos de la práctica docente. Se propone un momento inicial, corregulado con un fuerte apoyo directivo de una orientadora, en que se busquen estrategias que permitan al profesor/a iniciar la reflexión a partir de su propio modelo didáctico sobre el proceso de enseñanza-aprendizaje. De esta manera, como veremos, se promueve que cada profesor/a trabaje dentro de su ZDP respecto al proceso de enseñanza-aprendizaje de las ciencias. Este momento suministra la base necesaria para realizar acciones posteriores correguladas dentro del grupo y autorreguladas por cada profesor/a

\section{Metacognición, regulación y cambio en la formación del profesorado}

Un segundo aspecto en el que se fundamenta el modelo de formación aplicado es procurar que los profesores/as desarrollen habilidades metacognitivas que, a su vez, permitan la autorregulación de los cambios conceptuales, procedimentales y actitudinales con respecto al proceso de ense- 
ñanza-aprendizaje de la ciencia (Gunstone, y Northfield, 1994; White, y Mitchell, 1994; Baird, 1986)

El concepto de cambio es apropiado para analizar el contenido y los puntos de vista respecto a lo que se entiende por aprender, enseñar, ciencia escolar, sobre el papel del profesorado, de los estudiantes y de las interacciones en clase. En la propuesta desarrollada, el aspecto central de la construcción de nuevas concepciones pasa por reconocer que cualquier cambio está en las manos del propio enseñante, lo cual significa que es autorregulado. Es el propio enseñante quien tiene que reconocer las ideas relevantes para poder valorar esas ideas (concepciones, percepciones, creencias, habilidades y actitudes) en relación con los marcos teóricos de referencia. A partir de ello puede anticipar las decisiones alternativas posibles y decidir si reconstruye o no sus ideas. Aprender requiere la disposición (consentimiento y disponibilidad) y la actividad del que aprende.

Afirmar que el profesorado, por sí mismo, debe reconocer, valorar y decidir no implica que se esté disminuyendo el papel de la persona orientadora, ya que tiene la función difícil e importante de promover las actividades que posibiliten el reconocimiento, la valoración y la toma de decisiones. Por eso, entendemos que los procesos de cambio autorregulados por cada profesor generalmente se pueden dar cuando el proceso formativo ya haya avanzado bastante; esto exige planificar períodos de formación prolongados. Los momentos iniciales son de corregulación profesor/orientador y el proceso, siempre, será complementado por un componente de regulación mutua dentro de la comunidad crítica de la que los profesores forman parte.

Otro aspecto a destacar es que los cambios raramente significan el completo abandono de una noción en favor de otra, sino que generalmente significan la adición de nuevas ideas, la adaptación de las anteriores y la adquisición de la noción del contexto en el cual el nuevo punto de vista o concepción es más apropiado. De ahí que esta propuesta se base en un trabajo lento, a largo plazo y contextualizado.

Para que el profesorado tenga la información y la autodirección que le permita reconocer, evaluar y decidir sobre la necesidad de reconstruir sus ideas y su práctica, es necesario que lleve a cabo una reflexión de tipo metacognitivo. Por eso, los conceptos de cambio profesional y metacognición son totalmente interdependientes (Gunstone y Northfield, 1994).

Flavell (1976), autor que introduce el término, define la metacognición como el conocimiento que el sujeto posee acerca de sus propios procesos cognitivos y productos o sobre algo relacionado con esos procesos. Actualmente también se refiere a la regulación de esos procesos. La metacognición actúa posibilitando la formación de esquemas mentales o representaciones dinámicas que surgen como producto de las experiencias resultantes de las actividades del sujeto sobre la realidad, y su mecanismo principal es la reflexión; cada acto metacognitivo tiene lugar a través de un proceso de reflexión (Labarrere, 1994).
El aspecto crucial del proceso de cambio se basa en que los profesores y profesoras construyan decisiones fundamentadas teóricamente respecto a la reconstrucción de sus concepciones personales, percepciones, actitudes, creencias, prácticas. Por fundamentadas entendemos reconocidas y evaluadas con respecto a la comprensión de las metas de las decisiones y al uso relevante del conocimiento, habilidades, estrategias y estructuras que deben ser aprendidas. Pero, para que las concepciones y las prácticas puedan evolucionar, es necesario poseer conocimientos y habilidades de tipo metacognitivo. Como consecuencia, el aprendizaje de conocimientos didácticos y el aprendizaje de estrategias metacognitivas son tareas inseparables e interdependientes.

Por otro lado, se deben facilitar las condiciones que «animen» al profesorado a asumir el riesgo intelectual que supone este enfoque. Esto relaciona la propuesta experimentada con otra línea de trabajo fundamental: el apoyo a los profesores para que asuman las decisiones. Hablamos de asumir decisiones y no innovaciones, y esta terminología no es casual. Tiene sus raíces en el principio de que todo proceso metacognitivo debe ir acompañado del fortalecimiento y preservación de la autoestima del profesor o profesora. Consecuentemente, el proceso de toma de conciencia no debe basarse sólo en aquello que se pretende innovar o cambiar, sino también en aquellos aspectos que se consideren positivos y, por lo tanto, se quieran preservar.

Muchas veces, en este modelo de formación, la experiencia puede tener lugar antes que la comprensión, y ello también supone un riesgo. El trabajo en grupo, con el apoyo de los compañeros/as, (el «coleguismo»), es una de las formas efectivas de apoyo, ya que fortalece a cada una de las personas implicadas en el proceso.

La transcripción de los siguientes fragmentos ejemplifican reflexiones metacognitivas por parte de las profesoras. También evidencia cómo se han producido cambios $\mathrm{y}$ que los mismos fueron corregulados entre profesora y orientadora.

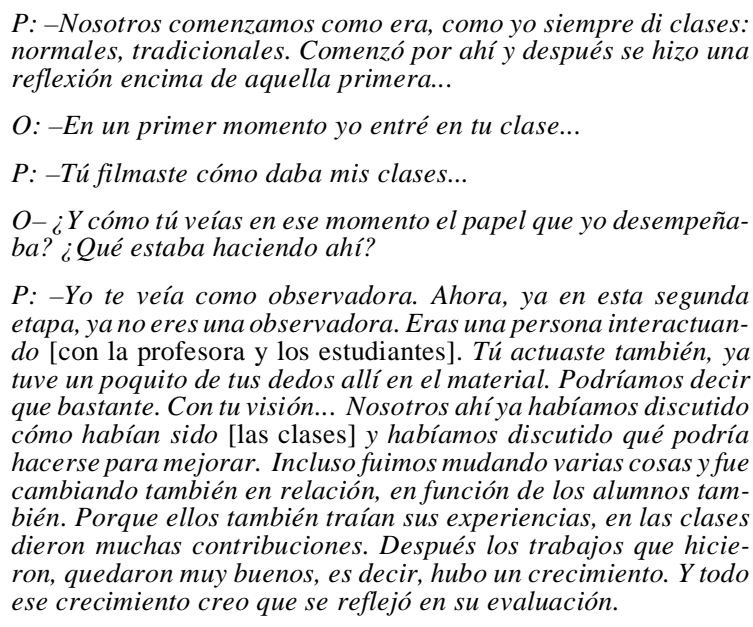

P:-Nosotros comenzamos como era, como yo siempre di clases. normales, tradicionales. Comenzó por ahí y después se hizo una reflexión encima de aquella primera...

O: -En un primer momento yo entré en tu clase..

$P$ : -Tú filmaste cómo daba mis clases...

O- ¿Y cómo tú veías en ese momento el papel que yo desempeñaba? ¿Qué estaba haciendo ahí?

P: -Yo te veía como observadora. Ahora, ya en esta segunda etapa, ya no eres una observadora. Eras una persona interactuando [con la profesora y los estudiantes]. Tú actuaste también, ya tuve un poquito de tus dedos allí en el material. Podríamos decir que bastante. Con tu visión... Nosotros ahí ya habíamos discutido cómo habían sido [las clases] y habíamos discutido qué podría hacerse para mejorar. Incluso fuimos mudando varias cosas y fue cambiando también en relación, en función de los alumnos también. Porque ellos también traían sus experiencias, en las clases dieron muchas contribuciones. Después los trabajos que hicieron, quedaron muy buenos, es decir, hubo un crecimiento. Y todo ese crecimiento creo que se reflejó en su evaluación. 
Figura 3

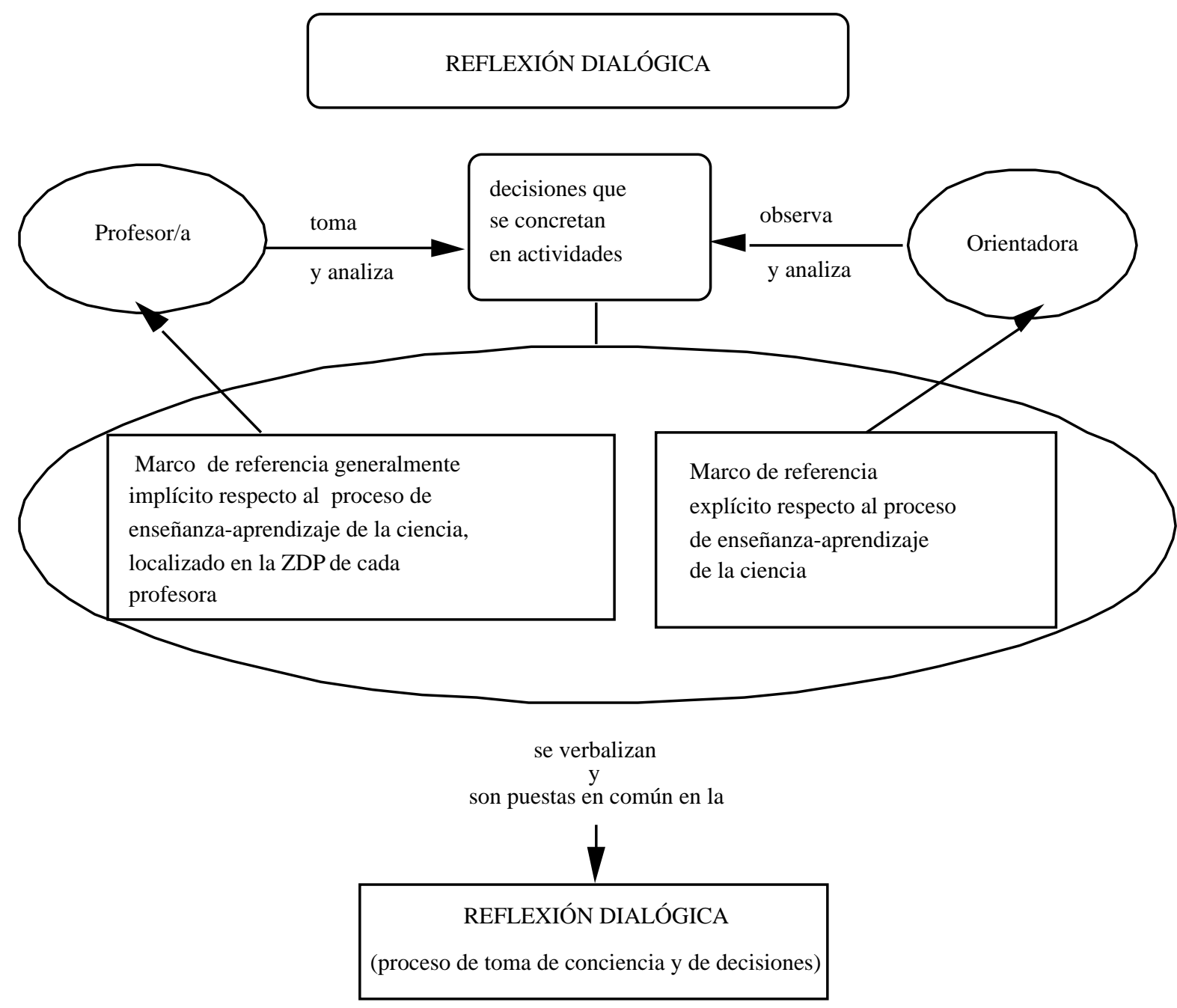

En este modelo, la reflexión dialógica se establece en función de problemas situados en un espacio concreto, en función de los cuales, enseñante y orientador/a, en un proceso corregulado, realizan una toma de conciencia y de decisiones sobre aquello que les satisface y aquello que creen necesario cambiar.

En esta segunda transcripción, además del proceso metacognitivo realizado se observa que la profesora explicita aspectos tratados en la reflexión inicial que favorecieron su proceso de cambio. Están relacionados con lo que podríamos llamar estímulo a la autoestima, y en los que se propició que la toma de decisiones estuviera relacionada no sólo con aspectos a innovar sino también con los que se consideraba conveniente mantener.
$O:-i Y$ que te pareció la experiencia de verte [en la filmación en vídeo] y escucharte [en la cinta de audio grabada]?

$P:-Y o$ encontré que eso es importante. Porque no tenemos noción de los errores que cometemos. Porque entramos en una clase. damos clase, salimos y ya vamos a dar otra clase. Y así siempre. De esa manera no conseguimos detenernos a pensar, para tener noción de la dimensión de lo que se está haciendo. Y en el momento en que me ví, encontré que era válido, que era importante para nosotros tener conciencia de lo que hacemos, de los errores y de las cosas buenas también. Vi cosas buenas también, no solamente malas. 
En los fragmentos siguientes se evidencian cambios, inicialmente corregulados $\mathrm{y}$, posteriormente, en una etapa más avanzada, asumidos de forma autorregulada por la profesora.

O: - Mira, Rosa, yo también pienso que eso no es algo simple y fácil de elaborar. Sin embargo, si pensamos que es por ese camino que tenemos que ir... te propongo pensar juntas. ¿Qué te parece? Vamos a recordar esto para tenerlo en cuenta al preparar juntas la próxima unidad.

P:-iMe parece óptimo! Tú me conoces y sabes que entusiasmo y buena voluntad no me faltan. Sola no sabría qué hacer. Ahora, con tu ayuda...

P: -Y ahora, después del aparato circulatorio, nos centramos en el aparato respiratorio, y preparé un material así, semejante. Creo que no fue con la misma calidad de los materiales que vimos, pero fue en el mismo estilo y su respuesta [la de los alumnos] también fue la misma, bien positiva.

O: - ¿Y continuaste con la misma dinámica, por ejemplo, de plantear problemas para pensar en ellos, de pedir que hicieran lecturas previas?

P: -Sí, fue el mismo esquema. El mismo esquema. Claro que no tenía materiales para proyectar, pero ahí yo hice algunas innovaciones.

Estos otros fragmentos ilustran reflexiones metacognitivas sobre el proceso de formación que las profesoras están realizando.

P: -Ahí la primera cosa, que yo... no sé si consigo expresarlo claramente... la importancia, en mi opinión, de este trabajo. Reforzó la importancia que ya le daba. Creo que es una manera de parar para pensar. Creo que es extremadamente válido. Ya valió la pena por eso. Incluso que a partir de esto no hiciésemos nada más; ya fue valioso este detenerse a observarnos, a leer la reunión y ver las grabaciones del vídeo. Creo que fue así, formidable. Ya fue un aspecto, ¿verdad?, que encontré positivo. Otra cosa, respecto de la organización del trabajo, eso de tener las opiniones de otras personas respecto del tema. Sentí que muchas veces pensamos teóricamente casi la misma cosa, la línea de ideas respecto de algunos temas son prácticamente las mismas: la importancia que se da para los alumnos; esa visión centrada en el alumno/a, que ellos son el objetivo de nuestra enseñanza. Eso también fue bueno, porque más o menos como yo pensaba, vi que otras personas también. [...]

O: -[Dijiste] que encuentras que es una situación difícil ver las propias clases [en el vídeo] pero que todo el mundo de alguna forma debería verse. Me lo explicas un poco...

P: -Sí, es simple. Porque, si te observas en la cinta, ves una montaña de errores, una montaña de cosas que pueden cambiar, que no se ven sólo hablando. Hay un momento, si comienzas a remirar lo que hiciste, que dices: ¡Podría hacerlo diferente! Por ejemplo, cuando en aquella clase usé aquel cartel, realmente pensé que era muy bonito, pero ahora vi que el que se sienta en el fondo no ve nada, tenía que ser algo mayor, bien diferente; cosas que, si no las veo en la cinta, no me doy cuenta.

La mediación de la reflexión dialógica en la formación del profesorado

Como ya se ha indicado, la concepción en que se encuadra este modelo propone la formación del profesorado mediada por la reflexión. Se postula que la esencia de ese proceso no va a ser una actividad individual de autorreflexión, sino la reflexión dialógica producto de un proceso corregulado, primero especialmente entre cada profesora y la orientadora, para posteriormente crear una comunidad crítica de reflexión y de acción respecto al proceso de enseñanza-aprendizaje de la biología.

La concepción de «reflexión dialógica» se fundamenta en el concepto de interacción social, entendida como estrategia privilegiada para promover y facilitar la construcción del conocimiento, tanto en el profesorado (en relación con su conocimiento didáctico) como en el alumnado (en relación con su conocimiento de las ciencias). Este concepto está íntimamente ligado a los trabajos de Vygotsky y sus discípulos. Desde la teoría sociocultural se considera que la experiencia individual se alimenta, se expande y se profundiza a través de la apropiación de la experiencia social que es vehiculada por el lenguaje (Vygotsky, 1989b; Wertsch, 1988). Incorporamos esta idea al modelo propuesto, ya que entendemos que la calidad de los intercambios que sean mediados por la reflexión dialógica entre profesores/as y orientadora va a tener relación con la calidad del proceso de formación de cada profesor/a.

Los diálogos, sean de la díada profesora-orientadora o ampliados para un grupo, constituyen un encuentro de sujetos portadores de concepciones y experiencias diversas que se disponen a compartir. En una situación inicial, las profesoras tienen mayor riqueza de conocimientos con relación a las características que contextualizan su trabajo. La orientadora, por su parte, ha profundizado con mayor detenimiento en las teorías en las que se basa el marco referencial de la actividad de formación. En los encuentros se propiciará la reflexión dialógica, y son momentos privilegiados para ir negociando y aproximando las concepciones y experiencias de cada uno. En ese sentido, si bien la base de trabajo que se propone es una actividad dialógica, es fundamental que todos los que dialogan tengan ideas estructuradas que se disponen a compartir. Por eso, se parte de estrategias que permitan esa estructuración.

La figura 3 resume aspectos fundamentales que caracterizan este processo de reflexión dialógica.

Los fragmentos que siguen ejemplifican cómo se concreta esa actividad dialógica. En la primera transcripción se observa que, adoptando la forma de un proceso corregulado, se parte del análisis que hace la profesora de las actividades realizadas por ella. La orientadora, que también observó y analizó las clases de la profesora, retoma el tema y propone reflexionar sobre él abstrayendo ideas generales, en el marco de referentes teóricos.

P: -Ellos [los estudiantes] se identifican con aquellas cosas interesantes, tipo grupos sanguíneos [...] entonces, la importancia de eso [...] la polialelia ligada a los grupos sanguíneos, eso llamó la atención; en cambio, la parte de pelaje de los conejos, fue totalmente falto de interés, yo creo.

O:-Estoy de acuerdo. Podríamos cambiar partiendo de esa idea del interés de los alumnos por el tema. Creo que podríamos 
profundizar más en ello... También hice un análisis de tus clases y estoy de acuerdo con muchos aspectos de lo que has dicho. Te propongo que retomemos algunos detalles concretos de las clases ¿Cual podría ser el motivo por el que aquel tema fue interesante para los estudiantes?

En este otro fragmento se hace referencia a una reflexión evaluativa sobre la práctica realizada después de una reflexión anterior en que se tomaron decisiones.

\begin{abstract}
P: -El objetivo que nos propusimos fue modificar las clases, la manera cómo se trabajaba el contenido, de manera que hubiese un mejor aprovechamiento por parte de los alumnos, de manera más significativa, más accesible, sin tanta terminología.

O: -¿Qué más? ¿Qué otros aspectos tuvimos en cuenta en relación con el conocimiento?

P: -jAh! Desprendernos de los términos difíciles y usar una terminología más fácil de comprender por los estudiantes. No hablar inicialmente de sístole y diástole y sí de contracción y relajamiento. No usar los términos sangre arterial y venosa y sí sangre cargada de oxígeno, sangre cargada de gas carbónico, facilitando el aprendizaje.

O: -En realidad usamos mucho esos términos. Sin embargo, ¿de qué manera? $Y$, ¿por qué eso facilitaría el aprendizaje?

$P$ : -Siempre que usamos un término difícil [científico], que los estudiantes no conocían, fue después de haber entendido de que hablábamos. Porque de esa manera ellos no tienen que usar términos que no saben lo que significan.

O: -Entonces podrías decir: cuando se introduce terminología, debe ser una terminología "cargada de significado»

P: -Que sea fácil para ellos entender lo que están leyendo. Es lo mismo que sucedería si de repente yo quisiera leer un libro lleno de vocabulario técnico, por ejemplo, de ingeniería; no lo entendería. Entonces, terminología con significado, que sea más fácil, que la lectura sea más accesible.
\end{abstract}

La adopción de una actitud de promover la toma de conciencia y de decisiones a partir de un proceso reflexivo-dialógico entre profesora y orientadora parece conducir a que una actuación similar se produzca entre la profesora y el grupo de alumnos y alumnas.

O: -Fue una cosa muy bonita. [Profesora y orientadora han reflexionado respecto a lo interesante que resultó la organización de la clase para viabilizar el trabajo en pequeños grupos. Sin embargo la orientadora se preocupa con el constante cambio de organización al iniciar y terminar la clase. Comparte su inquietud con la profesora. Ésta, a su vez, lo discute con los estudiantes y les pide su opinión y propuestas de decisión]. Tú les dijiste [a los estudiantes] «María Inés me dijo esto, pero ustedes ¿que piensan?»Fue un momento interactivo entre orientadora-profesoraalumnos/as, todos trabajando y opinando. Eso es justamente lo que no existe cuando hay una gestión autoritaria de la enseñanza. Yo diría que fue un claro ejemplo de una ideología que tiene por base compartir y construir juntos la realidad del aula.

P:-Claro, lo creo muy importante, ese compartir. Es sólo por eso que todavía estoy enseñando, porque creo muy importante ese intercambio. Siento que cada día aprendo mucho con ellos.

\section{La construcción del conocimiento en la ZDP de cada profesor/a}

Este último aspecto que postulamos como base para el método de formación de profesores, al igual que el anterior, recoge aportes del movimiento sociocultural. Como vimos, dentro de esta teoría, se entiende el hombre como un ser esencialmente social que acaba de constituirse y desarrollarsse como sujeto en la relación con el próximo, en una actividad práctica común. Vygotsky dice que las funciones psicológicas del individuo se construyen en la medida en que se utilizan, y que todas aparecen dos veces, primero en el nivel social y después en el individual (de lo interpsicológico a lo intrapsicológico) (Vygotsky,1989a).

En relación con estas ideas, Vygotsky estableció una diferencia entre el aprendizaje que una persona es capaz de hacer sola, individualmente, y el que es capaz de hacer gracias a la colaboración del profesor/a o compañeros/as más expertos. Para explicarlo elaboró el concepto de zona de desarrollo próximo (ZDP). Aunque su trabajo se vincula a estudios realizados con niños, su potencial es genérico y en nuestro caso lo aplicamos a la relación que se establece tanto entre la orientadora y cada profesora como de las profesoras entre sí. Como dice Cazden (1981), la ZDP posibilita la actuación antes de la competencia. Ésta es potenciada por la interacción «con los otros». Minick (1987) habla de la transición de la consideración del individuo «en tanto que individuo» a la consideración del individuo «en tanto que en actividad social».

La ZDP establece un nivel de dificultad. Este nivel, que se supone como el próximo, debe ser desafiante, pero posible de alcanzar. En función de ello, la metodología de formación propuesta parte de la hipótesis de que, difícilmente, en un corto período de tiempo, el profesor/a puede avanzar, desde un modelo didáctico inicial a modelos didácticos preconizados por las modernas teorías del campo de la didáctica de las ciencias. El objetivo es que, lentamente, se vayan introduciendo avances que conduzcan hacia esos modelos a través de modelos intermedios posibles de alcanzar en la ZDP de cada profesora. Trabajar dentro de este concepto significa evaluar la actuación sin objetivos finales rígidos. La evaluación del proceso no se hace con respecto al alcance de metas finales predeterminadas sino con respecto al avance posible dentro de la ZDP de cada profesora, y se analiza a partir del proceso vivido.

Así, en este proceso, se parte del encuentro entre quien está inmerso en el contexto y, por tanto, lo conoce y lo puede evaluar, pero que generalmente tiene ideas implícitas sobre su trabajo, y quien ha analizado las concepciones modernas del proceso enseñanza-aprendizaje de la ciencia y, por lo tanto, puede ayudar a que se produzca ese proceso de explicitación de lo implícito para promover que se tomen decisiones fundamentadas. Las ayudas que el profesor/a recibe de los otros (orientador/a o compañeros/as) se transforman e interiorizan y, finalmente, se usan estos mismos medios de guía para dirigir la propia actuación en futuras soluciones de problemas.

El cambio dentro de una ZDP suele caracterizarse por un cambio individual, o sea, por la capacidad de hacer independientemente algo que antes sólo se podía hacer con ayuda. Sin embargo, lo fundamental en el concepto 
de ZDP se refiere a la contrastación entre el aprendizaje aislado y el rendimiento en las actividades en colaboración. El foco de atención debemos ponerlo, entonces, en la apropiación y el dominio de las formas de mediación, evaluada no sólo ni necesariamente a través del aprendizaje independiente después de la práctica guiada, sino mediante la capacidad para participar en actividades colaborativas cualitativamente nuevas.

Trabajar dentro de la ZDP de cada profesor/a significa posibilitar que avance hasta lo que él/ella potencialmente pueda alcanzar en actividades colaborativas con la orientadora y con compañeros/as que hayan avanzado más en el proceso de toma de consciencia y decisiones. El trabajo se vinculará con sus conocimientos, creencias y prácticas concretas y pensamos que el conocimiento de los contenidos específicos de la disciplina que enseña no es algo secundario, sino un elemento básico de la acción. Por ello este modelo se basa en la formación del profesorado, interactuando con el orientador y los compañeros, dentro del área específica de la didáctica de las ciencias.

Finalmente resaltamos que es este trabajo en la ZDP lo que da sentido a la necesidad de partir de la reflexión de la díada orientadora-profesora. Partimos de la hipótesis de que los modelos habituales «orientador-grupo de profesores» dificultan el trabajo en la ZDP en profundidad y por ello habitualmente se producen pocos cambios. En este modelo de formación la colaboración, en un primer momento, se da entre cada profesora y la orientadora, pues los modelos didácticos de las profesoras son muy dispares y se cree necesario establecer un apoyo orientador de la colega (orientadora) que ha reflexionado respecto a los actuales modelos del proceso de enseñanza-aprendizaje de la ciencia. En las sucesivas fases se irá orientando el proceso cada vez más hacia una regulación mutua entre profesores autónomos que se apoyan desde la posibilidad de su propia autorregulación del proceso.

Las transcripciones que siguen pretenden ilustrar aspectos de cómo se concretó el trabajo de la orientadora con la profesora, procurando tener como espacio de actuación aquél que cada profesor pudiese alcanzar en las actividades colaborativas.

La primera transcripción se refiere a una de las profesoras cuyo camino reflexivo se sitúa dentro de su no-conformidad con el trabajo que está realizando. Desde el momento en que se la invita a participar en el proyecto, esa actitud se hace muy evidente. Ella, durante su época de estudiante y en sus primeros años como profesora de ciencias, fue una persona entusiasta y preocupada por conocer ideas nuevas, innovar. Luego, los años de trabajar sin un grupo con el que intercambiar inquietudes, las difíciles condiciones de trabajo le hicieron cambiar de actitud y entrar en una rutina con la cual no está conforme. Termina repitiendo muchos de los vicios existentes en el sistema. Sin embargo ella es crítica frente a eso, está angustiada y quiere volver a aquella actitud abierta hacia los cambios que antes manifestaba.
P: -;Oh!, creo que el trabajo que estás proponiendo es interesante, principalmente porque así vamos a salir de la rutina. Como te dije aquel día, mi trabajo está siendo rutinario y me siento muy mal con eso, pues acabo [...] girando y girando siempre en lo mismo. Los alumnos no se interesan en criticar la forma cómo se les enseña y ahí una va entrando en la rutina. Creo que es interesante el trabajo que estás haciendo.

Las siguientes transcripciones muestran que la profesora toma conciencia de acciones con las que no está de acuerdo y, a partir de ello, se dispone a introducir cambios. Sin embargo, no sabe como concretarlos sola, necesita el apoyo colaborativo de la orientadora.

O: -Como ves, te estoy situando en otra alternativa: vamos a partir de discutir ejemplos que sean próximos a la vida de los alumnos/as y vamos a tener como meta lle gar a modelos biológicos, más abstractos, sin embargo, no memorizados sino elaborados por los estudiantes. ¿Qué piensas de todo esto? ¿Qué ideas te sugiere?

P:-Creo muy interesante todo esto que dices. Estoy de acuerdo. Sería mucho más útil e interesante para los alumnos/as. Sin embargo, en este momento no sabría qué decir, cómo trabajar de esa manera. Estoy de acuerdo en eliminar el ejemplo del pelaje de los conejos, pues eso fue, como dices, solamente por seguir el libro didáctico y, ahora que lo pienso, no era necesario. Ahora, sinceramente, tengo dificultades en pensar cómo hacer eso de partir de esos ejemplos y llegar al concepto de polialelia.

O: - Mira, Carme, yo también pienso que eso no es algo simple y fácil de elaborar. Sin embargo, si pensamos que es por ese camino que tenemos que ir... te propongo pensar juntas ¿Qué te parece? Vamos a recordarlo para tenerlo en cuenta al preparar juntas la próxima unidad.

P: - iMe parece óptimo! Tú me conoces y sabes que entusiasmo y buena voluntad no me faltan. Sola no sabría qué hacer, ahora, con tu ayuda...

P:-Pienso que debería haber estimulado más el razonamiento de los alumnos. Creo que doy muchas respuestas, demasiado pronto para ellos. Debería haber estimulado más ese aspecto. Hay momentos en que pregunto y yo misma respondo. No doy oportunidad para que puedan pensar y razonar. Eso es una cosa que tengo que cambiar. Y tal vez me podrías orientar en eso porque ya procuré pensar varias maneras de intentar no dar la respuesta, pero ellos no responden y yo acabo respondiendo. Entonces, creo que es que no he estimulado suficientemente su razonamiento. No sé si tú tendrías [sugestiones de cómo cambiar].

Obsérvese en este otro fragmento que el trabajo con otra de las profesoras se sitúa dentro de una concepción mucho más pesimista y menos entusiasta respecto de las posibilidades de un trabajo inovador. El trabajo de formación permanente de esta profesora se sitúa dentro de otra ZDP, que se propondrá estimular una inconformidad con el trabajo que está realizando, como condición previa a asumir posturas innovadoras.

P.- María Inés, te conozco hace años, yo sé tus ideas. Desde que me propusiste este trabajo, sé perfectamente lo que quieres. Lo encuentro muy válido, creo que hay que cambiar, que hay que intentar alguna cosa. Creo que tu reforma tendría que hacerse también en primer grado, era una de las propuestas que ya pensaba el año pasado antes de hablar contigo [...] Y pienso que tiene que hacerse. Sólo pienso que va a ser una cosa difícil de implantar, que principalmente no tenemos tiempo, no tenemos estímulo y no tenemos recursos. 
En el ejemplo de la tercera profesora (parte de transcripción ya fue citada anteriormente), que también corresponde a un momento inicial del trabajo, se observa que se siente segura y se considera innovadora. De esta manera el trabajo con ella puede caracterizarse como desarrollado en otra ZDP que se diferencia de cada uno de los dos casos anteriores.

P: -Bueno, en mi propuesta, por lo que creo, por las cosas a las que doy crédito, creo que estoy yendo bien. Creo que no me gustaría haber dedicado más tiempo a la conversación "por que sí» «nada a ver». Incluso que yo crea que el tema sea importante, lo dejaría para otra hora, no sé... Claro que depende del asunto también [...] Concuerda con lo que yo pienso.

\section{ALGUNAS CONSIDERACIONES FINALES}

En este escrito hemos pretendido sintetizar y ejemplificar las principales concepciones que han fundamentado una experiencia de implantación de una metodología para la formación permanente del profesorado de ciencias.

Evidentemente, dichas concepciones no son inéditas y aparecen también como referencial de todo un grupo de investigadores que están trabajando dentro de ideas similares a las que dan base a este trabajo, muchos de los cuales se citan en el texto. Lo que sí consideramos innovador es la combinación de los cuatro referentes y su aplicación en un determinado contexto - población-con relación al cual se concreta la propuesta de formación permanente.

Creemos que todo proyecto de formación del profesorado, para ser eficaz, debe ser planificado específicamente en función de las características de la comunidad escolar en la que quiere incidir, tanto la de los centros, como la del profesorado y la de las personas que puedan ejercer como orientadoras. Por ejemplo, este proyecto no tiene como objetivo promover una transmisión de ideas o de «consignas didácticas» iguales para todos los enseñantes, ni se podría aplicar si la orientadora no fuera una persona bien aceptada por las profesoras. Pero tampoco tendría sentido si no tuviera la finalidad de crear una comunidad de profesores innovadores y críticos en la población donde se aplica.

En este modelo de formación, la investigación didáctica, crítica y prospectiva está estrechamente ligada al campo específico de la actuación del profesorado (aquello que enseña) y se dirige a proponer avances concretos y prácticos. A la vez, tiene en cuenta las innovaciones curriculares normativas que se están implantando. Éstas, si se presentan sin estar acompañadas de las demás perspectivas, corren el peligro de ser algo externo al trabajo de los profesores en el aula y quedar como una norma en el papel pero que en nada incide en la práctica.

La experiencia ya realizada y las acciones de continuidad en que estamos trabajando actualmente, tanto en la formación permanente como en la aplicación de este mismo modelo a la formación inicial, han aportado datos y han permitido análisis que nos llevan al convencimiento de que ésta es una forma de actuación efectiva en relación con la cual se van concretando logros, lentos pero consistentes, con respecto a la mejora del proceso de enseñanza-aprendizaje de las ciencias en el aula. Los límites de extensión del artículo nos impiden discutir estos resultados, que pretenden ser motivo de un artículo posterior. De cualquier forma, en el presente trabajo nuestro objetivo fue dar a conocer, y someter al análisis de otros grupos preocupados con la formación del profesorado, los principios sobre los cuales se estruturó un modelo de formación de profesores e ejemplificar estos principios con transcripciones de su aplicación a un contexto de formación permanente.

\section{REFERENCIAS BIBLIOGRÁFICAS}

AJUNTAMENT DE BARCELONA (1990). Pla de Formació Permanent Institucional per a les Escoles Municipals de l'Ajuntament de Barcelona. Àrea d'Educació de l'Ajuntament de Barcelona (documento interno).

ASTOLFI, J.P.(1998). Desarrollarun currículo multirreferenciado para hacer frente a la complejidad de los aprendizajes científicos. Enseñanza de las Ciencias, 16(3), pp. 375-385.

ASTOLFI. J.P., PETERFALVI, B. y VERIN, A. (1991). Compétences methodologiques en sciences expérimentales. París: INRP.
BAIRD, J.R. (1986). Improving learning through enhanced metacognition: a classroom study. European Journal of Science Education, 8(3), pp. 263-282.

BAIRD, J.R., FENSHAM, P.J., GUNSTONE, R.F. y WHITE, R.T. (1991). The importance of reflection in improving science teaching and learning. Journal of Research in Science Teaching, 28(2), pp. 163-182.

BRISCOE, C. y PETERS, J. (1997). Teacher collaboration across and within schools: supporting individual change in elementary science teaching. Science Education, 81(1), pp. 51-65. 
CARR, W. (1996). Una teoría para la educación. Hacia una investigación educativa crítica. Madrid: Morata.

CAZDEN,C. (1981). Performance before competence: assistance to child discourse in the zone of proximal development. Quarterly newsletter of the laboratory of comparative human cognition, 3(1), pp. 5-8.

CLARKE, A. (1994). Student-teacher reflection: developing and defining a practice that is uniquely one's own. International Journal of Science Education, 16(5), pp. 497-509.

COBERN,W.W. (1996). Worldview theory and conceptual change interactions in science education. Science Education, 80(5), pp. 579-610.

DARSIE, M.M.P. y CARVALHO, A.M.P. (1996). O início da formação do professor reflexivo. Revista da Faculdade de Educação da USP, 22(2).

DEPARTAMENT D'ENSENYAMENT (1987). Avaluació de l'experiència pilot de formació permanent institucional de mestres de Cornellà: (FOPI-1982-1984). Barcelona: Generalitat de Catalunya.

DOMINGOS, A. (1989). Influence of the social context of the school on the teacher's pedagogical practice. British Journal of Sociology of Education, 10(3), pp. 351- 366.

ENGUITA, M.F. (1985). Trabajo escuela e ideología. Madrid: Akal-Universitaria.

ESCUDERO, J.M (1991). La naturaleza del cambio planificado en educación: cambio como formación y formación para y como cambio, en Escudero, J.M. y López Yáñez (coord.). Los desafios de las reformas escolares: Cambio educativo y formación para el cambio. Sevilla.

FLAVELL, J.M. (1976). Metacognitive aspects of problem solving, en Resnick, L. (eds.). The nature of intelligence. Hillsdale, Nueva Jersey: Erlbaum.

GIL, D. y PESSOA A.M.(1994). Enseñanza de las ciencias, en Formación del profesorado de las ciencias y la matemática. Madrid: Popular.

GIMENO SACRISTÁN, J. (1991). El currículo: una reflexión sobre la práctica. Madrid: Morata.

GRUNDY, S. (1991). Producto o praxis del curriculum. Madrid: Morata.

GUESS-NEWSOME, J. y LEDERMAN, N.G. (1993). Preservice biology teachers' knowledge structures as a function of professional teacher education: a year-long assessment. Science Education, 77(1), pp. 25-45.

GUNSTONE, R.F. y NORTHFIELD, J. (1994). Metacognition and learning to teach. International Journal of Science Education, 16(5), pp. 523-537.

GUSTAFSON, B. y ROWEL, P. (1995). Elementary preservice teachers: constructing conceptions about learning science, teaching science and the nature of science. International Journal of Science Education, 17(5), pp. 589-605.

HASWEH, M.Z. (1996). Effects of science teachers' epistemological beliefs in teaching. Journal of Research in Science Teaching, 33(1), pp. 47-63.
KEMMIS, S. (1993). La formación del profesor y la creación de comunidades críticas de profesores. Investigación en la Escuela, 19, pp. 15-38.

LABARRERE, A.F. (1994). Pensamiento, análisis y autorregulación en la actividad cognoscitiva de los alumnos. México: Ángeles Editores.

MELLADO, V. (1996). Concepciones y prácticas de aula de profesores de ciencias, en formación inicial de primaria y secundaria. Enseñanza de las Ciencias, 14(3), pp. 289-302.

MINICK, N. (1987). Implications of Vygotsky's theories for dynamic assessment, en Lidz, C.S. Dynamic assessment: an interactional approach to evaluating learning potential. Nueva York: Longman.

MITCHELL, I. (1994). School-tertiary collaboration: a longterm view. International Journal of Science Education, $16(5)$, pp. 599-612.

PÉREZ GÓMEZ, A. (1992). El pensamiento pedagógico de los profesores: un estudio empírico sobre la incidencia de los cursos de aptitud pedagógica (CAP) y de la experiencia profesional en el pensamiento de los profesores. Investigación en la escuela, 17, pp. 51-73.

PERRENOUD, P. (1993). Práticas pedagógicas, profissão docente e formação: perspectivas sociológicas. Portugal: Dom Quixote.

PORLÁN, R. (1994). Las concepciones epistemológicas de los profesores: el caso de los estudiantes de magisterio. Investigación en la escuela, 22, pp. 67-84.

PORLÁN, R. y RIVERO, A. (1998). El conocimiento de los profesores. Sevilla: Díada.

SANMARTÍ, N. y IZQUIERDO, M. (1997). Reflexiones en torno a un modelo de ciencia escolar. Investigación en la escuela, 32, pp. 51-62

SCHÖN, D. (1983). The reflective practitioner. Londres: Temple Smith.

SHULMAN, L.S. (1989). Paradigmas y programas de investigación en el estudio de la enseñanza: una perspectiva contemporánea, en Wittrock. La investigación de la enseñanza. I. Enfoques, teorías y métodos. Barcelona: Paidós

VYGOTSKY, L.S. (1989a). A formação social da mente. O desenvolvimento dos processos psicológicos superiores. São Paulo: Martins Fontes.

VYGOTSKY, L.S. (1989b). Pensamento e Linguagem. São Paulo: Martins Fontes.

WERTSCH, J.V. (1988). Vygotsky y la formación social de la mente. Barcelona: Paidós

WHITE, R.T. y MITCHELL, I.J. (1994). Metacognition and the Quality of Learning. Studies in Science Education, 23, pp. 21-37.

ZEICHNER, K.M. (1995). Los profesores como profesionales reflexivos y la democratización de la reforma escolar, en Fundación Paideia. Volver a pensar la educación (Vol. II). Prácticas y discursos educativos (Congreso Internacional de Didáctica). Madrid: Morata. 